\title{
Hazardous trace elements and naturally occurring radionuclides in coal and coal combustion residuals from India
}

\author{
Zhen WANG ${ }^{1}$, Debabrata DAS ${ }^{2}$, AvNER VEnGOSH $^{1 *}$ \\ ${ }^{1}$ Nicholas School of the Environment, Duke University, \\ Durham, NC 27708, USA (*correspondence: \\ vengosh@duke.edu) \\ ${ }^{2}$ Department of Geology, Panjab University, Chandigarh, \\ 160014, India
}

India is the second largest producer of thermal coal and the third largest energy consumer in the world, and the consumption of thermal coal in India is likely to continue to increase in the next decade [1]. However, the presence of hazardous elements and naturally occurring radioanuclides in coal may pose risks to the environment and human health during production and combustion of coal and disposal and management of coal combustion residuals (CCRs) and thus warrants careful investigation.

Here we report the concentrations of 15 hazardous trace elements (V, Cr, Mn, Co, Ni, Cu, As, Se, Cd, Sb, Ba, Tl, Pb, $\mathrm{Th}$, and $\mathrm{U}$ ) and the activities of 3 naturally occurring radionuclides $\left({ }^{226} \mathrm{Ra},{ }^{210} \mathrm{~Pb}\right.$, and $\left.{ }^{228} \mathrm{Ra}\right)$ in coal $(\mathrm{n}=12)$ and CCR samples $(\mathrm{n}=10)$ from Nagpur and Pathakhera areas in India. Our data show that the coals are notably enriched in $\mathrm{Se}, \mathrm{Co}, \mathrm{Cr}, \mathrm{Th}, \mathrm{V}, \mathrm{Ni}, \mathrm{Cu}, \mathrm{Pb}, \mathrm{Ba}, \mathrm{Mn}$, and $\mathrm{U}$ (enrichment factor $(\mathrm{EF})>1.2)$, while depleted in $\mathrm{As}, \mathrm{Sb}, \mathrm{Cd}$, and $\mathrm{Tl}(\mathrm{EF}<$ $0.8)$ relative to the average of world coal [2]. In contrast, the CCRs are depleted in most of the elements relative to the average of world coal ash [2], except for Se and Th (EF > 1.2). The mean total $\mathrm{Ra}\left({ }^{226} \mathrm{Ra}+{ }^{228} \mathrm{Ra}\right)$ activity of the coals $(63.4 \mathrm{~Bq} / \mathrm{kg})$ is much higher than that of the U.S. coals $(34.7$ $\mathrm{Bq} / \mathrm{kg}$ ), whereas the mean total Ra activity of the CCRs $(186.8 \mathrm{~Bq} / \mathrm{kg})$ is lower than that of the U.S. CCRs $(264.3$ $\mathrm{Bq} / \mathrm{kg})$, yet still greater than that of the common soil $(\sim 70$ $\mathrm{Bq} / \mathrm{kg}$ ) [3]. Due to the high volatility of $\mathrm{Pb}$ during coal combustion, a non-equilibrium between ${ }^{226} \mathrm{Ra}$ and ${ }^{210} \mathrm{~Pb}$ is observed in the CCRs, with ${ }^{210} \mathrm{~Pb}$ preferably being enriched in fly ash while depleted in bottom ash. Overall, our data provide vital information for further evaluating and tracking the environmental impact associated with coal production and combustion as well as disposal and beneficial use of CCRs in India.

[1] Coal in India 2019, https://www.industry.gov.au/oce. [2] Ketris and Yudovich (2009), Int. J. Coal Geol., 78(2), 135148. [3] Lauer et al. (2015), Environ. Sci. Technol., 49 (18), 11227-11233. 